\title{
The PD-1:PD-L1 axis in Inflammatory Arthritis
}

\author{
Mary Canavan ${ }^{1,2^{*}}$ D, Achilleas Floudas ${ }^{1,2}$, Douglas J. Veale ${ }^{2}$ and Ursula Fearon ${ }^{1,2}$
}

\begin{abstract}
The activation of antigen specific T cells during an immune response is a tightly regulated process at the level of both costimulatory and coinhibitory receptors. One such coinhibitory receptor or checkpoint inhibitor which has received much attention in the field of oncology is the programmed cell death protein 1 (PD-1). Blockade of PD-1 or its ligand PD-L1 has proven successful in the treatment of a wide variety of cancers, therefore highlighting an important role for this pathway in anti-tumour immune responses. However, a caveat of PD-1 therapy and boosting anti-tumour immune responses is the development of self-reactive $T$ cells which can lead to the induction of various autoimmune or inflammatory diseases, referred to as immune- related adverse events (irAEs). The emergence of rheumatological irAEs such as Inflammatory Arthritis (IA) in recent years has highlighted the importance of PD-1 in maintaining self-tolerance. Furthermore, the emergence of rheumatology related irAEs raises an important question as to how defects in this pathway can contribute to spontaneous rheumatological disease. In this review, we describe the biological distribution, function and regulation of the PD-1 pathway, its potential role in IA and irAE related IA.
\end{abstract}

Keywords: Checkpoint inhibitors, PD-1, Rheumatoid arthritis, Psoriatic arthritis, Adverse events

\section{Background}

It is widely appreciated that costimulation of $\mathrm{T}$ cells via antigen presenting cells (APC) is an essential step in boosting the immune system and inducing antigen specific $\mathrm{T}$ cell responses. Costimulatory receptors such as CD80 and CD86, expressed on the surface of APC, bind the CD28 molecule on T cells, driving proliferation and cytokine production. Following resolution of infection, coinhibitory receptors become upregulated to prevent destruction of host tissues and to restore homeostasis [1]. Therefore, both positive and negative signals are required to regulate $\mathrm{T}$ cell function. Programmed cell death protein 1 (PD-1) acts as a negative regulator or immune checkpoint inhibitor (ICI) of $\mathrm{T}$ cell responses. The PD-1 axis acts as an essential pathway to restore

\footnotetext{
* Correspondence: mary.canavan3@gmail.com

${ }^{1}$ Department of Molecular Rheumatology, Trinity Biomedical Sciences Institute, Trinity College Dublin, Dublin 2, Ireland

${ }^{2}$ EULAR Centre of Excellence, Centre for Arthritis \& Rheumatic Diseases, St.

Vincent's University Hospital, University College Dublin, Dublin, Ireland
}

tolerance and prevent the accumulation of self-reactive $\mathrm{T}$ cells [2]. This review centres on the PD-1 pathway, its long-appreciated role in tolerance and more recent advances on its role in autoimmune diseases and cellular metabolism. Furthermore, we will examine the regulation of this checkpoint inhibitor in Inflammatory Arthritis (IA), while discussing the emergence of IA in ICI treated patients in the cancer setting.

\section{PD-1 expression, signalling and regulation}

PD-1 (also known as CD279) is a $55 \mathrm{kDa}$ type I transmembrane protein belonging to the $\mathrm{CD} 28$ superfamily of immunoreceptors. It is primarily expressed on immune cells such as T, B and NK cells, in addition to monocytes, macrophages and dendritic cells (DC). However, to date, studies exploring PD-1 signalling and its functions have been performed predominantly on $\mathrm{T}$ cells. While PD-1 is usually absent on naïve T cells, its expression following antigen engagement of the $\mathrm{T}$ cell

(c) The Author(s). 2021 Open Access This article is licensed under a Creative Commons Attribution 4.0 International License, which permits use, sharing, adaptation, distribution and reproduction in any medium or format, as long as you give appropriate credit to the original author(s) and the source, provide a link to the Creative Commons licence, and indicate if changes were made. The images or other third party material in this article are included in the article's Creative Commons licence, unless indicated otherwise in a credit line to the material. If material is not included in the article's Creative Commons licence and your intended use is not permitted by statutory regulation or exceeds the permitted use, you will need to obtain permission directly from the copyright holder. To view a copy of this licence, visit http://creativecommons.org/licenses/by/4.0/. The Creative Commons Public Domain Dedication waiver (http://creativecommons.org/publicdomain/zero/1.0/) applies to the data made available in this article, unless otherwise stated in a credit line to the data. 
receptor (TCR), is significantly upregulated $[3,4]$. Once this antigen is sufficiently cleared, the PD-1 receptor is then subsequently downregulated. However, during periods of chronic infection or indeed cancer, where elimination of antigen in its entirety is inefficient, PD-1 expression remains high. Previous studies have highlighted that in these settings of chronic antigen encounter (i.e. chronic infection and cancer), $\mathrm{T}$ cells become exhausted rendering them unable to secrete cytokines, proliferate or perform their effector functions $[5,6]$. In this setting, high expression of PD-1 is a hallmark of exhausted T cells [7].

PD-1 interacts with two known ligands, PD-L1, also known as $\mathrm{B} 7-\mathrm{H} 1$ or CD274 and PD-L2, also known as B7-DC or CD273. PD-L1 is expressed on a wide variety of cell types including $\mathrm{T}$ and $\mathrm{B}$ cells, macrophages, DC and mast cells, in addition to being expressed in tissues such as heart, lung, kidney and liver. The expression of PD-L2 however, appears to be more restricted, being detected only on APCs such as macrophages and DC, where its expression is regulated by cytokines including IFN- $\gamma$, GMCSF and IL-4 $[8,9]$. The expression of PD-L1 is regulated in response to numerous cytokines such as type I and type II interferons, IL-10, IL-17, IL-6, IL-4, IL-1 $\beta$ and IL-27 [10-13]. In addition to regulation by the aforementioned cytokines, PD-L1 expression is also induced by a number of signalling pathways and pattern recognition receptors. Specifically, NFkB, MAPK, HIF and STAT3 have all been implicated in PD-L1 induction [12, 14-16]. Moreover, following engagement of the pattern recognition receptors TLR4 and TLR3, PD-L1 expression is also regulated $[17,18]$. PD-1 preferentially ligates to PD-L1 over PD-L2 for reasons not fully


Fig. 1 Mechanisms of action of PD-1. During immunological synapse formation, ligation of PD-1 with PD-L1 leads to the recruitment of SHP-2 at the ITSM site of PD-1 and subsequent dephosphorylation of PI3K, AKT and RAS dampening down TCR mediated signalling, top left panel. Due to inhibition of PI3K and RAS, PD-1 can change the metabolic profile of the T cell by limiting GLUT-1 expression and mitochondrial availability of glucose, favouring fatty acid oxidation over glycolysis, top right panel. There is a paucity of data on the role of B cell PD-1, however it has been suggested that PD-1 leads to inhibition of SYK resulting in reduced B cell proliferation and cytokine production following B cell receptor (BCR) mediated activation, bottom left panel. A recently proposed mechanism of action for macrophage PD-1 expression is binding to PDL-1 in cis and therefore limiting available PD-L1 for ligation with T cell PD-1, bottom right panel 
understood at present. While PD-1:PD-L2 has a higher binding affinity compared to PD-1:PD-L1, PD-L2 is generally expressed at lower levels than PD-L1, thus favouring a PD-1:PD-L1 partnership [19]. Following ligation with PD-L1, activated PD-1 can antagonize the TCR signal transduction pathway through several mechanisms. Firstly, PD-1 is expressed as a monomer on the cell surface, where it consists of an extracellular immunoglobulin-like binding domain, a transmembrane region and a cytoplasmic domain which contains two tyrosine motifs - an inhibitory motif (ITIM) and an immunoreceptor switch motif (ITSM) [20]. A conformational change in the PD-1 receptor is induced following ligation to PD-L1, thus resulting in the phosphorylation of both tyrosine motifs - ITIM and ITSM by Src family kinases [21-23]. Subsequently, SHP-1 and SHP-2 tyrosine kinases are recruited, resulting in the dephosphorylation of several kinases which can inhibit both TCR and CD28 mediated signals leading to a reduction in $\mathrm{T}$ cell proliferation, survival and cytokine production [24-28] (Fig. 1, top left panel). Bidirectional signalling following PD-L1 ligation may also occur, however, studies into this area are limited, in part due to the lack of evidence identifying intracellular signal transduction pathways downstream of PD-L1 activation. Until recently, no identifiable cytoplasmic signal transductions motifs were identified on PD-L1. However, a recent study by GatoCanas et al. elegantly identified functional regulatory signal motifs within the intracytoplasmic domain of PD-L1 which may be responsible for PD-L1 reverse signalling [29]. While the specific signalling pathways induced by PD-L1 reverse signalling is unclear, effects of PD-L1 activation on APC have been reported. DC treated with soluble PD-1 (sPD-1) exhibit decreased maturation profiles and increased production of IL-10 [30]. Moreover, within the context of inflammatory disease, autoantibodies to PD-L1 have been identified within the serum of Rheumatoid Arthritis (RA) patients which can facilitate bidirectional PD-L1 signalling on T cells. Specifically, PD-L1 activation on $\mathrm{T}$ cells induced increased secretion of IL-10, in addition to a small increase in IFN- $\gamma$ secretion [31].

The regulation of PD-1 expression on $\mathrm{T}$ cells is dependent on the context of antigen exposure, whereby acute or chronic infection (or the persistence of tumour antigen in the cancer setting) dictates the transcriptional pathways used to regulate its expression. Following $\mathrm{T}$ cell activation through the TCR, the inducible transcription factors, nuclear factor of activated T cells 1c (NFAT1c) and Notch are responsible for the initial expression of PD1 in both $\mathrm{CD}^{+}$and $\mathrm{CD} 8^{+} \mathrm{T}$ cells $[32,33]$. However, these transcription factors are dispensable for the maintenance of PD-1 expression during chronic infection. The transcription factor forkhead box protein $\mathrm{O} 1$ (FoxO1) has been identified as a key regulator of PD-1 expression during chronic inflammation, whereby high expression of FoxO1 inhibits T-bet expression [34]. Given that T-bet is a previously identified repressor of PD-1, inhibition of Tbet via FoxO1 leads to the accumulation of PD-1 on $\mathrm{T}$ cells [35]. NFAT1c has also been implicated in driving PD-1 expression in B cells [36]. Moreover, in addition to $\mathrm{T}$ and $\mathrm{B}$ cells, the regulation of PD- 1 has also been examined in macrophages, whereby $\mathrm{NF \kappa B}$ signalling mediates PD-1 expression following TLR stimulation [36]. While PD-1 is mainly upregulated on T cells in response to antigen via TCR signalling, antigen independent PD-1 regulation has also been described. Kinter et al. demonstrated an induction in PD-1 expression on peripheral blood T cells in response to the common gamma chain cytokines IL-2, IL-7, IL-15, and IL-21 [37]. Furthermore, antiinflammatory cytokines such as IL-10 and TGF- $\beta$ have also been shown to regulate PD-1 expression on T cells $[38,39]$.

\section{PD-1 and tolerance}

The first evidence for the key role of PD-1 in regulating $\mathrm{T}$ cell tolerance was discovered following the generation of PD-1 $1^{-/-}$mice. PD-1 deficient $\mathrm{T}$ cells were hyperproliferative and upon introduction of the lpr mutation, PD$1^{-/-}$mice developed more severe lupus like disease compared to PD- $1^{+/+}$littermates [40]. PD-1 is expressed by $\mathrm{CD} 4^{-} \mathrm{CD} 8^{-}$double negative (DN) $\mathrm{T}$ cells during thymic development [41]. In the absence of PD-1, there is a reported increase in $\mathrm{CD}_{4}^{+} \mathrm{CD}^{+}$double positive (DP) $\mathrm{T}$ cells, providing evidence for a PD-1 mediated augmentation of positive selection in the thymus. The effect of PD-1 on thymic T cell development is not monospecific either, since PD-1 exerts a negative effect on the selection of the TCR $\beta$ chain that can lead to bias of the T cell repertoire [41]. In a more recent study, Jiang et al. demonstrated that PD-1 limits the escape of high affinity autoreactive $\mathrm{CD} 4^{+} \mathrm{T}$ cells from the thymus. The authors tracked individual autoreactive $\mathrm{T}$ cell clones transferred to lymphopenic recipient mice and observed that PD-1 expression can limit the expansion of autoreactive $\mathrm{T}$ cells in specific tissues, therefore creating a link between PD-1 deprivation and autoimmunity [42]. Upon antigen recognition, $\mathrm{T}$ cells become arrested by APC, preventing their migration away from the immunological synapse thus enabling appropriate $\mathrm{T}$ cell-APC signalling to occur. Following $\mathrm{T}$ cell activation and cytokine production, $\mathrm{T}$ cells can subsequently regain their motility and minimise cytokine production. During these T cell-APC interactions, $\mathrm{T}$ cell $\mathrm{PD}-1$ expression is upregulated and the $\mathrm{T}$ cell fine tunes the time spent at this immunological synapse. In the absence of PD-1, the length of the $\mathrm{T}$ cell-APC interaction increases, therefore resulting in increased pro-inflammatory cytokine production [43]. The effect of PD-1 on $\mathrm{T}$ cell velocity and motility is 
specific to PD-1 and potentially dependent on antigen availability, with CTLA-4 (Cytotoxic $\mathrm{T}$ lymphocyte antigen-4) not exhibiting a similar effect [44]. Interestingly, PD-1:PD-L1 and PD-1:PD-L2 interactions are potentially not equal in their capacity to maintain peripheral $\mathrm{T}$ cell tolerance. In a mouse model of diabetes, PD-L1 blockade inhibited $\mathrm{T}$ cell tolerance, while PD-L2 blockade did not [45]. PD-1 is rapidly upregulated following TCR engagement and can effectively block $\mathrm{T}$ cell transition from naïve to effector $\mathrm{T}$ cell, however anergic $\mathrm{T}$ cells have a similar PD-1 expression level to effector $\mathrm{T}$ cells and do not become invigorated following PD-1 blockade [46, 47]. PD-1 blockade can also affect $\mathrm{T}$ cell chemokine expression by enhancing effector $\mathrm{T}$ cell CXCR3 expression, therefore inducing migration to the target tissue [47].

In addition to the capacity of the PD-1:PD-L1 axis to regulate effector $\mathrm{T}$ cell responses, emerging evidence suggests a key role for PD-1 in the development and function of $\mathrm{T}$ regulatory cells (Treg). Tregs can regulate the immune response by utilising contact dependent and contact independent mechanisms of action. These cells are characterised by high expression of the transcription factor Foxp3 and the IL-2 receptor $\alpha$ chain (CD25) [48]. Treg cells perform immunosuppressive functions in a contact dependent manner through CTLA-4. CTLA-4 is constitutively expressed by Treg cells and binds with high affinity to CD80 and CD86 leading to decreased availability of CD28 mediated costimulation and T cell activation. In addition to CTLA-4, PD-1 ligation has also been reported to maintain expression of Foxp3, with PD-L1 being essential for the in vitro induction of Treg cells through downregulation of the mTOR pathway [49]. PD-1 engagement of Th1 cells in vivo has been shown to induce plasticity and lasting conversion of Th1 cells to Tregs, which is dependent on intact downstream signalling of PD-1 [50]. The immunosuppressive capacity of Tregs is not restricted to the $\mathrm{T}$ cell compartment, with Treg cells being able to suppress activation and autoantibody production specifically of autoreactive PD$1^{+} \mathrm{B}$ cells in a PD-1:PD-L1dependant manner [51].

The effect of PD-1 on immune tolerance is not restricted to $\mathrm{T}$ cells, some B cells, macrophages and DC also express PD-1, however the role(s) of PD-1 expression on these cells appear pleiotropic and remain poorly understood. Recent murine studies indicate that tumour associated macrophages (TAM) maintain high expression of PD-1 that correlate negatively with their capacity to phagocytose tumour cells [52]. PD-1 expressing TAM maintain an M2-like phenotype with high expression of CD206. These cells are potentially infiltrating macrophages that have originated from the bone marrow [52]. Similar to macrophages, PD-1 expressing human DC have been shown to limit anti-tumour immunity by suppressing $\mathrm{CD}^{+} \mathrm{T}$ cell $\mathrm{IL}-2$ and IFN- $\gamma$ production [53]. Engagement of PD-1 on macrophages and DC can have pleiotropic effects leading to enhanced rather than suppressed immune responses. This is based on the observation that PD-1 can bind PD-L1 expressed by the same cell in cis, therefore, limiting the availability of PDL1 on the APC [54] (Fig. 1, bottom right panel). This cis interaction of PD-1:PD-L1 is an additional functional mechanism used within the PD-1 pathway, in addition to the more common method of trans activation reported in the previous section above. A small population of peripheral blood B cells also express PD-1. While there is a paucity of evidence, initial studies show that $B$ cell PD-1 expression is a result of $B$ cell receptor (BCR) engagement and dampens down $\mathrm{BCR}$ mediated signalling by recruitment of SHP-2 [55] (Fig. 1, bottom left panel). PD-1 expressing B cells have also been shown to accumulate in thyroid tumours, and while they do not express higher IL-10 than PD-1 negative B cells, they were able to suppress $\mathrm{T}$ cell responses in a PD-1:PD-L1 dependent manner [56].

\section{PD-1 and metabolism}

It is now widely appreciated that the activation, proliferation and effector functions of immune cells are intrinsically linked to cellular metabolism. Cellular bioenergetics are adapted towards the specific functional requirements of the cell, and in addition to meeting cellular ATP demands, also provide biosynthetic intermediates. In the context of autoimmune disease, specifically Rheumatoid Arthritis (RA) and Psoriatic Arthritis (PsA), we and others have shown that altered cellular bioenergetics due to mitochondrial dysfunction, oxidative stress and hypoxia, drive pro-inflammatory processes in the synovial tissue in inflamed diarthrodial joints. Moreover, nutrient supply and signalling pathways such as HIF- $1 \alpha$, NFkB, Notch-1 and JAK-STAT have also been shown to mediate metabolic changes in RA [57-59]. While principally the main role of the PD- 1 pathway is to act as an inhibitory receptor for immune responses, reports are now emerging of a potential role for the PD-1:PD-L1 axis in metabolism. While activated $\mathrm{T}$ cells undergo rapid metabolic reprogramming to glycolysis to support their proliferation and effector functions, studies have shown that following PD-1 ligation, activated $\mathrm{T}$ cells no longer utilise glycolysis, glutaminolysis or metabolism of branched-chain amino acids, but instead use fatty acid oxidation (FAO) to generate energy [60]. Moreover, PD1 ligated $\mathrm{T}$ cells display a significant decrease in their expression of the glucose transporter Glut1, therefore impairing their ability to take up glucose (Fig. 1, top right panel). Patsoukis et al. demonstrated a reduction in the extracellular acidification rate (ECAR) and oxygen consumption rate $(\mathrm{OCR})$ in $\mathrm{PD}-1$ stimulated $\mathrm{T}$ cells, 
indicating an overall reduction in the ability of the cells to generate energy when glucose is the energy source. Furthermore, PD-1 activated $\mathrm{T}$ cells have increased spare respiratory capacities (SRC), thus enabling continued ATP production under increased cellular stress. Moreover, additional studies have demonstrated a reduction in cellular glycolysis following PD-1 ligation in vivo. Bengsch et al. explored the role of PD-1 signalling in exhausted $\mathrm{CD}^{+} \mathrm{T}$ cells during chronic lymphocytic choriomeningitis virus (LCMV) infection. They demonstrated that exhausted $\mathrm{T}$ cells had reduced oxidative phosphorylation, decreased glucose uptake and reduced glycolysis, mediated in part, by the PD-1 pathway [61]. Oganda et al. recently suggested the mitochondria itself may be the main target of the PD-1 inhibitory pathway. The authors reported a reduction in mitochondrial polarization and a decrease in several genes involved in mitochondrial structure and function in $\mathrm{CD}^{+} \mathrm{T}$ cells following PD-1 stimulation. Importantly, this led to a decrease in the number and length of mitochondrial cristae, suggesting an impairment in glucose metabolism may be in part due to mitochondrial dysfunction [62].

\section{The PD-1 pathway in inflammatory arthritis}

The PD-1:PD-L1 axis has been examined in Inflammatory Arthritis in an effort to understand how negative regulators function in the context of chronic inflammation. The expression of PD-1 and its ligand PD-L1 are upregulated in the RA synovium within lymphoid aggregates of the sub lining layer. We previously examined the PD-1:PD-L1 pathway within RA disease progression and subsequently demonstrated a significant increase in synovial PD-1 expression in early and established RA compared to both healthy control and Osteoarthritis (OA) synovial tissue. Furthermore, the expression of the PD-1 ligands, PD-L1 and PD-L2 were significantly increased in both early and established RA as well as arthralgia and undifferentiated IA [63]. Previous studies have also confirmed that histological expression of PD-1 correlates with the degree of synovial inflammation [64]. sPD-1 has also been detected in RA and PsA synovial fluid and serum, while being absent in OA [65]. sPD-1 levels are also increased in the serum of ACPA-positive but not ACPA-negative RA patients [63]. Interestingly, PD-1 has also been detected within extracellular vesicles (EV) in RA plasma and synovial fluid [66]. We and others have identified PD-1 expression on $\mathrm{CD} 4^{+}$and $\mathrm{CD}^{+} \mathrm{T}$ cells within the RA and PsA synovium $[63,65,67,68]$. The frequency of PD- 1 expressing $\mathrm{CD}^{+}{ }^{+}$and $\mathrm{CD} 8^{+} \mathrm{T}$ cells is also significantly elevated in RA synovial fluid compared to RA peripheral blood [69]. Here, the expression of PD-1 on these synovial fluid $\mathrm{T}$ cells correlates with disease activity [69]. Interestingly, PD-1 expression is absent on OA synovial T cells, suggesting its expression may be involved in IA pathogenesis rather than merely a consequence of inflammation [70]. Within the periphery, a decrease in the percentage of circulating $\mathrm{CD} 4^{+}$and $\mathrm{CD} 8^{+} \mathrm{PD}-1^{+}$cells in the blood of PsA and RA patients, respectively, has also been reported [71, 72]. In the context of myeloid cells, PD-L1 is expressed on synovial fluid $\mathrm{CD} 1 \mathrm{c}^{+}$dendritic cells [68], in addition to synovial fluid macrophages [67]. Moreover, PD-1-/- mice develop more severe arthritis, while PDL1.Fc treatment can inhibit the development of collagen induced arthritis (CIA) [64] and polymorphisms in PD-1 are associated with increased risk of developing RA [73]. To date, no previous studies have directly examined the effect of biologic or disease-modifying antirheumatic drugs (DMARD) treatment on the PD-1:PD-L1 axis in IA. However, the role that the therapeutically targeted cytokines, TNF $\alpha$ and IL- 6 have on the PD-1 pathway has previously been examined by Bommarito et al. This study demonstrated that while PD-L1 activation in healthy $\mathrm{CD} 4^{+} \mathrm{T}$ cells results in decreased $\mathrm{T}$ cell proliferation, this effect is abrogated in the presence of the pro-inflammatory cytokines TNF $\alpha$, IL- 6 or IL-1 $\beta$. Moreover, upon addition of the anti-TNF $\alpha$ drug adalimumab, anti-IL-6R drug tocilizumab or anti-IL-1 $\beta \mathrm{mAb}$, these cytokine-mediated effects are reversed and PD-L1 mediated T cell suppression is restored [65]. Furthermore, we previously demonstrated that the gene signature induced by the antagonistic antiPD-1 antibody, nivolumab (representing genes enriched as a result of inhibition on the PD-1:PD-L1 axis), is enriched in early and established RA patients. Upon examination of the effect of treatment on this enrichment, we noted a reduction in this enrichment signature in early RA synovial tissue following DMARD treatment, suggesting that DMARD treatment may normalise the PD-1 pathway in RA [63].

While the overexpression of the PD-1 pathway in RA may appear contradictory given the persistence of activated and proliferating $\mathrm{T}$ cells within the synovium, Wan et al. also provide evidence to justify this corollary. High levels of sPD-1 were identified in RA synovial fluid, which can antagonise the function of PD- $1^{+} \mathrm{T}$ cells. Studies by Bommarito et al. confirmed these findings in RA and subsequently reported similar results in PsA, whereby increased sPD-1 in PsA SF may counteract PD1 mediated $\mathrm{T}$ cell suppression [65]. Furthermore, upon examination of the function of $\mathrm{PD}-1^{+} \mathrm{T}$ cells in RA, Raptopoulou et al. demonstrated a less pronounced PD1 mediated reduction in T cell proliferation in RA synovial $\mathrm{T}$ cells compared to peripheral blood, suggestive that $\mathrm{T}$ cells within the synovium may be more resistant to PD-1 mediated suppression [64]. Moreover, we have previously reported a lack of PD-L1 positive cells in the RA synovium, and as mentioned above, a decrease in the PD-1 pathway gene signature in RA (i.e. enrichment of the nivolumab gene signature). Taken together, our data 
and that of others suggest that although PD-1 is present, the pathway may be dysfunctional or indeed the ligand may not be readily available within the RA synovium $[63,64]$. A recent study by Sugiura et al. elegantly demonstrated that high expression of CD80 on DC can restrict the PD-1 pathway during $\mathrm{T}$ cell activation [74]. The binding of CD80 to PD-L1 in cis on DC can subsequently interfere with the ability of PD-L1 to access PD1 on T cells. Given that high levels of CD80 on DC has previously been reported within the IA synovium, one could hypothesize that a CD80:PD-L1 interaction similar to that reported by Sugiura et al. could inhibit the PD-1 pathway in IA [75]. Taken together, we have depicted the potential contributions that the PD-1:PD-L1 axis may have in the pathogenesis of joint inflammation in IA in Fig. 2. As highlighted above, previous studies have demonstrated a potential role for PD-1 signalling in cellular bioenergetics, however, limited data exists on the bioenergetic requirements of $\mathrm{PD}-1^{+}$cells in IA. Given that PD $-1^{+}$cells in the synovium are resistant to PD-1 mediated suppression and do not appear to have an exhausted phenotype, it is tempting to hypothesize that the metabolic requirements of these cells may be aberrant to the metabolic profiles previously reported in infection models. Indeed, Petrelli et al. examined the metabolism of PD- $1^{+}$and $\mathrm{PD}-1^{-} \mathrm{CD} 8^{+} \mathrm{T}$ cells in synovial fluid and demonstrated that $\mathrm{PD}-1^{+} \mathrm{T}$ cells had increased rates of glycolysis compared to $\mathrm{PD}-1^{-} \mathrm{T}$ cells [76].

\section{Immune- related adverse events}

To date, antibodies to therapeutically target the PD-1: PD-L1axis have been approved for the treatment of a variety of cancers in the metastatic and adjuvant setting, including melanoma, non-small cell lung cancer (NSCL C), renal cell carcinoma (RCC), Hodgkin's lymphoma, bladder cancer, head and neck squamous cell carcinoma (HNSCC), Merkel-cell carcinoma, and microsatellite instable-high (MSI-H) or mismatch repair-deficient (dMMR) solid tumours. There are currently five FDAapproved immune checkpoint inhibitors targeting PD-1 (nivolumab, pembrolizumab), or PD-L1 (atezolizumab, durvalumab and avelumab). ICIs such as these have revolutionised the treatment of cancers by significantly

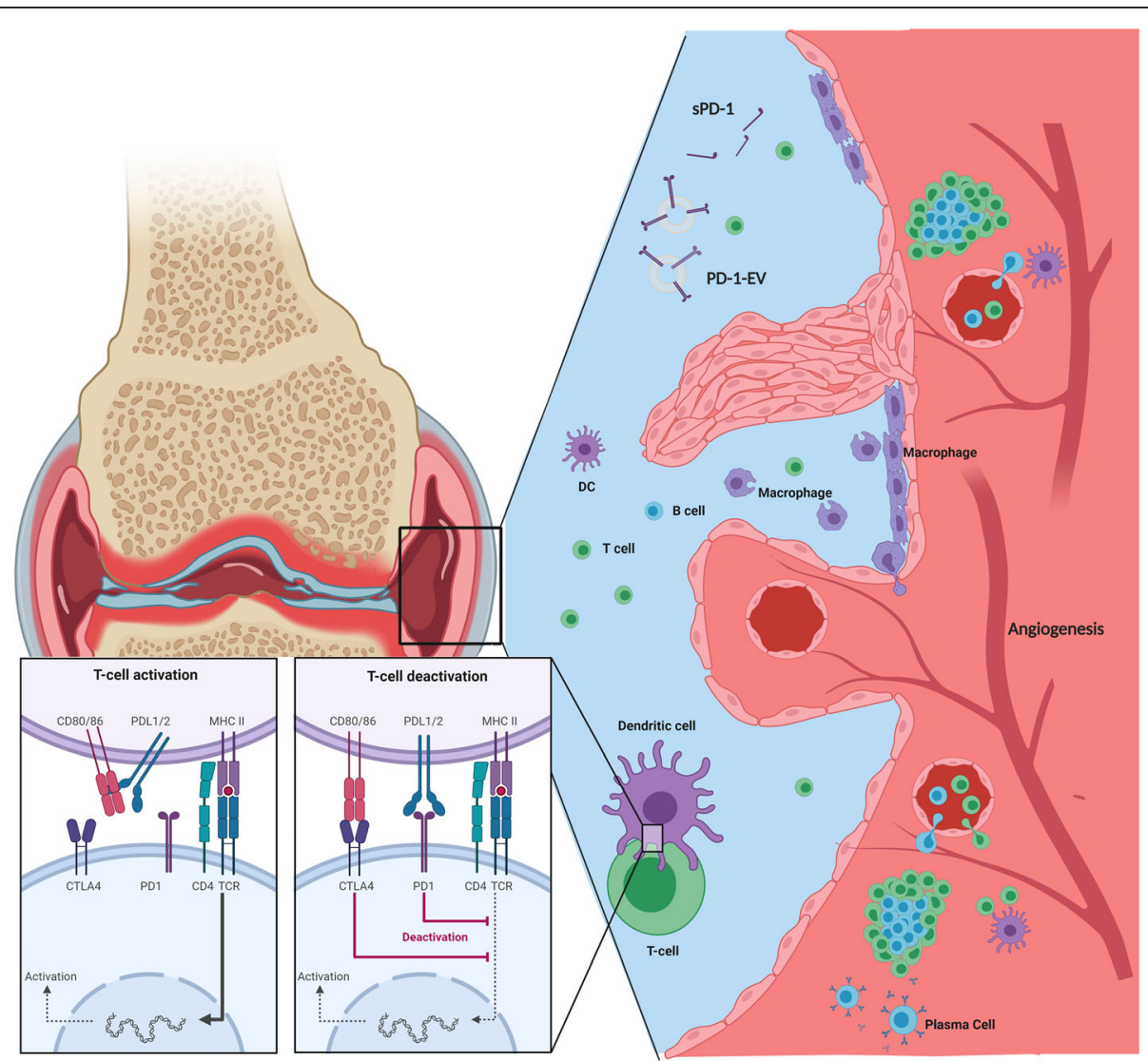

Fig. 2 The PD-1 pathway in Inflammatory Arthritis. Despite increased expression of PD-1 by CD4+ and CD8+ T cells in the synovial tissue of RA patients, increased SPD-1 and PD-1 carrying EV could inhibit PD-1 mediated T cell suppression. Additionally, availability of PD-L1 by synovial DC could be limited due to increased expression of CD80 and the binding of CD80 to PD-L1 in cis, therefore, reducing the functionally available PD-L1 
improving disease-free survival (DFS) and progressionfree duration. However, a caveat of ICI therapy and boosting anti-tumour immune responses is the development of self-reactive $T$ cells which can lead to the induction of various autoimmune or inflammatory diseases, referred to as immune- related adverse events (irAEs). IrAEs are distinct from chemotherapy induced side effects and can persist even after ICI cessation [77]. One such irAE which is becoming increasingly reported, is Inflammatory Arthritis. While exploration into this area is increasing, long term studies and large study cohorts are limited. Indeed, the first description of RA occurring after ICI treatment was in 2017, highlighting the novelty of this research area [78]. In addition to IA, sicca syndrome, myositis, vasculitis and polymyalgia rheumatica represent additional rheumatological irAEs, however IA irAEs appear to be the most common [79-81]. One study reported the development of arthralgia in $13.3 \%$ of patients treated with pembrolizumab or nivolumab for metastatic cutaneous malignancies [82], while others prospectively demonstrated the development of IA in $3.8 \%$ of patients treated with anti-PD-1: PD-L1 antibodies [83]. Although other irAEs such as colitis, pneumonitis and hypophysitis can develop early during ICI treatment, ICI induced IA possibly develops later in the course of immunotherapy and presents initially with small joint involvement similar to RA [84]. One study reported the manifestation of IA within 6-24 months following commencement of ICI therapy [85]. In those patients who go on to develop IA as a result of ICI treatment, Braaten et al. report that even after cessation of immunotherapy, IA persists [77]. Moreover, this persistent arthritis was less likely to improve in patients with longer ICI treatment duration and in those receiving combination ICI therapy (anti-CTL4 and anti-PD-1). Interestingly, reports of rheumatic irAEs in patients receiving anti-CTLA-4 immunotherapy are rare, suggestive of a more potent role for PD-1 in rheumatology related irAEs [86]. Treatment of IA in this unique cohort of patients may prove challenging given the need to administer immunosuppressive drugs to patients who have previously received immunostimulatory treatments. Hydroxychloroquine (HCQ) was examined as a first line DMARD in a single centre retrospective observational study. The authors used HCQ as a first-line steroidsparing agent and reported improvements in IA symptoms within their small sample size [87]. In another small case series, Kim et al. report a significant improvement in ICI induced polyarthritis symptoms in three patients in response to tocilizumab [88]. An important unanswered question remains whether use of these immunosuppressive drugs can affect tumour progression. However, early reports appear to be promising. Cappelli et al. demonstrated in a cohort of 60 patients with rheumatological irAEs, that there was no statistically significant increased risk of tumour progression following immunosuppressive treatment. The authors reassuringly reported no change in tumour response in patients treated with either DMARDs or TNF inhibitors [77]. In addition to ICI induced IA, patients may also concurrently develop additional non-rheumatological related irAEs. Cappelli et al. demonstrated within a cohort of 30 ICI induced IA patients, 31\% also developed colitis, while thyroid disease, pneumonitis and skin rash were also described within their cohort. These studies demonstrate how rheumatological irAEs can be successfully managed in cancer patients. However, future work should aim to examine therapeutic approaches that will minimize the risk of even developing irAEs in cancer patients undergoing anti-PD-1 treatment. While research into this area is limited, a recent encouraging study by Perez-Ruiz et al. suggests that prophylactic biologic treatment in patients receiving PD-1 immunotherapy may minimise the risk of developing irAEs. Specifically, the authors demonstrated that prophylactic blockade of TNF $\alpha$ before commencing anti-PD-1 (and anti-CTLA4) therapy prevents irAEs (specifically colitis) in mouse models. Importantly, the authors also report that addition of anti-TNF $\alpha$ therapy may also enhance the anti-tumour effects of the PD-1 treatment [89].

\section{Conclusion}

PD-1 is a pleiotropic molecule with a wider than initially described cellular distribution and function. While certain facets of the role of PD-1 in fine-tuning $\mathrm{T}$ cell responses have been studied extensively, there is a recent growing appreciation of the role of PD-1 in metabolism and cancer. Multiple studies have confirmed both the expression of PD-1 within the IA synovium and its correlation with disease activity or synovitis. It is therefore logical to assume that in the context of chronic inflammation in the joint, the inhibitory role of PD- 1 on $\mathrm{T}$ cell function is dysregulated or indeed absent. Furthermore, the emergence of IA irAEs in patients receiving PD-1: PD-L1 immunotherapy underscores the role diminished PD-1 signalling may have in the pathogenesis of IA. Importantly, the function of PD-1 in IA may be unique to other coinhibitory receptors or checkpoint inhibitors given that rheumatic irAEs have not been reported in patients receiving anti-CTLA-4 immunotherapy. Future studies should aim to delineate the function of PD-1 within the IA synovium to better understand how IA irAEs develop and can subsequently be prevented or treated.

\section{Abbreviations}

PD-1: Programmed cell death protein 1; irAEs: Immune- related adverse events; IA: Inflammatory Arthritis; APC: Antigen presenting cell; ICl: Immune checkpoint inhibitor; TCR: T cell receptor; NFAT1c: Nuclear factor of activated 
T cells 1C; TAM: Tumour associated macrophages; BCR: B cell receptor; FAO: Fatty acid oxidation; ECAR: Extracellular acidification rate; OCR: Oxygen consumption rate; SRC: Spare respiratory capacity; LCMV: Lymphocytic choriomeningitis virus; EV: Extracellular vesicles; CIA: Collagen induced arthritis; DC: Dendritic cell; NSCLC: Non-small cell lung cancer; RCC: Renal cell carcinoma; HNSCC: Head and neck squamous cell carcinoma; MSIH: Microsatellite instable-high; DFS: Disease free survival; NFKB: Nuclear Factor kappa-light-chain-enhancer of activated B cells; HIF: Hypoxia inducible factor; STAT: Signal Transducer and Activator of Transcription:; ITIM: Immunoreceptor tyrosine-based inhibitory motif; ITSM: Immunoreceptor tyrosine-based switch motif; FOXO1: Forkhead Box O1; CTLA: Cytotoxic Tlymphocyte-associated protein; ACPA: Anti-citrullinated protein antibody; DMARD: Disease-modifying antirheumatic drugs; HCQ: Hydroxychloroquine

\section{Acknowledgements}

Not applicable.

\section{Authors' contributions}

$M C$ designed the structure of the manuscript. AF designed the schematic in the manuscript. MC, AF, DJV and UF all contributed to the writing of this manuscript. All authors read and approved the final manuscript.

\section{Funding}

Not applicable.

\section{Availability of data and materials}

Not applicable.

\section{Ethics approval and consent to participate}

Not applicable.

\section{Consent for publication}

Not applicable.

\section{Competing interests}

Corresponding author Mary Canavan is an associate editor.

Received: 30 April 2020 Accepted: 3 November 2020

Published online: 11 January 2021

\section{References}

1. Chen L, Flies DB. Molecular mechanisms of T cell co-stimulation and coinhibition. Nat Rev Immunol. NIH Public Access. 2013;13:227-42. Available from: https://www.pmc/articles/PMC3786574/?report=abstract. [cited 2020 Aug 12].

2. Keir ME, Butte MJ, Freeman GJ, Sharpe AH. PD-1 and its ligands in tolerance and immunity. Annu Rev Immunol. 2008;26:677-704 Available from: https:// pubmed.ncbi.nIm.nih.gov/18173375/. [cited 2020 Aug 12].

3. Agata Y, Kawasaki A, Nishimura H, Ishida Y, Tsubata T, Yagita H, et al. Expression of the PD-1 antigen on the surface of stimulated mouse $\mathrm{T}$ and $\mathrm{B}$ lymphocytes. Int Immunol. 1996;8(5):765-72.

4. Riley JL. PD-1 signaling in primary T cells. Immunol Rev. 2009;229:114-25. Available from: http://www.ncbi.nlm.nih.gov/pubmed/19426218. [cited 2020 Mar 28].

5. Barber DL, Wherry EJ, Masopust D, Zhu B, Allison JP, Sharpe AH, et al. Restoring function in exhausted CD8 T cells during chronic viral infection. Nature. 2006;439(7077):682-7 Available from: http://www.ncbi.nIm.nih.gov/ pubmed/16382236. [cited 2020 Mar 28].

6. Pauken KE, Wherry EJ. Overcoming T cell exhaustion in infection and cancer. Trends Immunol. 2015;36:265-76 Elsevier Ltd.

7. Wherry EJ, Kurachi M. Molecular and cellular insights into T cell exhaustion. Nat Rev Immunol. 2015;15:486-99 Nature Publishing Group.

8. Ghiotto $M$, Gauthier L, Serriari N, Pastor S, Truneh A, Nunès JA, et al. PD-L1 and PD-L2 differ in their molecular mechanisms of interaction with PD-1. Int Immunol. 2010;22(8):651-60. Available from: https://academic.oup.com/ intimm/article-abstract/22/8/651/774506. [cited 2020 Mar 29].

9. Yamazaki T, Akiba H, Iwai H, Matsuda H, Aoki M, Tanno Y, et al. Expression of Programmed Death 1 Ligands by Murine T Cells and APC. J Immunol. 2002;169(10):5538-45 Available from: https://pubmed.ncbi.nlm.nih. gov/12421930/, [cited 2020 Jul 29].

10. Brown JA, Dorfman DM, Ma F-R, Sullivan EL, Munoz O, Wood CR, et al. Blockade of Programmed Death-1 Ligands on Dendritic Cells Enhances T
Cell Activation and Cytokine Production. J Immunol. 2003;170(3):1257-66 Available from: http://www.jimmunol.org/content/170/3/1257. http://www. jimmunol.org/content/170/3/1257.full\#ref-list-1. [cited 2020 Jul 29].

11. Curiel TJ, Wei S, Dong H, Alvarez X, Cheng P, Mottram P, et al. Blockade of B7-H1 improves myeloid dendritic cell-mediated antitumor immunity. Nat Med. 2003;9(5):562-7 Available from: https://pubmed.ncbi.nlm.nih.gov/12 704383/. [cited 2020 Jul 29].

12. Karakhanova S, Meisel S, Ring S, Mahnke K, Enk AH. ERK/p38 MAP-kinases and PI3K are involved in the differential regulation of $\mathrm{B} 7-\mathrm{H} 1$ expression in DC subsets. Eur J Immunol. 2009 ;40(1):254-266. Available from: https://doi. org/10.1002/eji.200939289. [cited 2020 Jul 29].

13. Karakhanova S, Bedke T, Enk AH, Mahnke K. IL-27 renders DC immunosuppressive by induction of B7-H1. J Leukoc Biol. 2011 ;89(6):837845. Available from: https://doi.org/10.1189/jlb.1209788. [cited 2020 Jul 29].

14. Huang G, Wen Q, Zhao Y, Gao Q, Bai Y. NF-kB Plays a Key Role in Inducing CD274 Expression in Human Monocytes after Lipopolysaccharide Treatment. Viola JPB, editor. PLoS One. 2013;8(4):e61602 Available from: https://dx.plos. org/10.1371/journal.pone.0061602. [cited 2020 Jul 29].

15. Noman MZ, Desantis G, Janji B, Hasmim M, Karray S, Dessen P, et al. PD-L1 is a novel direct target of HIF-1a, and its blockade under hypoxia enhanced: MDSC-mediated T cell activation. J Exp Med. 2014;211(5):781-90 Available from: www.jem.org/cgi/doi/10.1084/jem.20131916. [cited 2020 Jul 29].

16. Marzec M, Zhang Q, Goradia A, Raghunath PN, Liu X, Paessler M, et al. Oncogenic kinase NPM/ALK induces through STAT3 expression of immunosuppressive protein CD274 (PD-L1, B7-H1). Proc Natl Acad Sci U S A. 2008;105(52):20852-7 Available from: www.pnas.org/cgi/doi/10.1073/ pnas.0810958105. [cited 2020 Jul 29].

17. Pulko V, Liu X, Krco CJ, Harris KJ, Frigola X, Kwon ED, et al. TLR3-Stimulated Dendritic Cells Up-regulate B7-H1 Expression and Influence the Magnitude of CD8 T Cell Responses to Tumor Vaccination. J Immunol. 2009 183(6): 3634-3641. Available from: www.jimmunol.org/cgi/doi/10.4049/jimmunol. 0900974. [cited 2020 Jul 29].

18. Mezzadra R, Sun C, Jae LT, Gomez-Eerland R, De Vries E, Wu W, et al. Identification of CMTM6 and CMTM4 as PD-L1 protein regulators. Nature. 2017;549(7670):106-10 Available from: https://www.nature.com/articles/ nature23669. [cited 2020 Jul 29].

19. Ghiotto M, Gauthier L, Serriari N, Pastor S, Truneh A, Nunè JA, et al. PD-L1 and PD-L2 differ in their molecular mechanisms of interaction with PD-1. Int Immunol. 2010;22(8):651-60 Available from: https://academic.oup.com/ intimm/article-abstract/22/8/651/774506. [cited 2020 Mar 29].

20. Zhang X, Schwartz JCD, Guo X, Bhatia S, Cao E, Chen L, et al. Structural and functional analysis of the costimulatory receptor programmed death-1. Immunity. 2004;20(3):337-47.

21. Gauen LK, Zhu Y, Letourneur F, Hu Q, Bolen JB, Matis LA, et al. Interactions of p59fyn and ZAP-70 with T-cell receptor activation motifs: defining the nature of a signalling motif. Mol Cell Biol. 1994;14(6):3729-41.

22. Straus DB, Weiss $A$. Genetic evidence for the involvement of the Ick tyrosine kinase in signal transduction through the T cell antigen receptor. Cell. 1992;70(4):585-93.

23. Zak KM, Kitel R, Przetocka S, Golik P, Guzik K, Musielak B, et al. Structure of the Complex of Human Programmed Death 1, PD-1, and Its Ligand PD-L1. Structure. 2015;23(12):2341-8.

24. Chemnitz JM, Parry RV, Nichols KE, June CH, Riley JL. SHP-1 and SHP-2 Associate with Immunoreceptor Tyrosine-Based Switch Motif of Programmed Death 1 upon Primary Human T Cell Stimulation, but Only Receptor Ligation Prevents T Cell Activation. J Immunol. 2004;173(2):945-54.

25. Sheppard KA, Fitz L, Lee JM, Benander C, George JA, Wooters J, et al. PD-1 inhibits T-cell receptor induced phosphorylation of the ZAP70/CD3Z signalosome and downstream signaling to PKCO. FEBS Lett. 2004;574(1-3):37-41.

26. Hui E, Cheung J, Zhu J, Su X, Taylor MJ, Wallweber HA, et al. T cell costimulatory receptor CD28 is a primary target for PD-1-mediated inhibition. Science (80-). 2017;355(6332):1428-33.

27. Latchman YE, Liang SC, WU Y, Chernova T, Sobel RA, Klemm M, et al. PD-L1deficient mice show that PD-L1 on T cells, antigen-presenting cells, and host tissues negatively regulates T cells. Proc Natl Acad Sci U S A. 2004; 101(29):10691-6.

28. Freeman GJ, Long AJ, Iwai Y, Bourque K, Chernova T, Nishimura H, et al. Engagement of the PD-1 immunoinhibitory receptor by a novel B7 family member leads to negative regulation of lymphocyte activation. J Exp Med. 2000;192(7):1027-34.

29. Gato-Cañas M, Zuazo M, Arasanz H, Ibañez-Vea M, Lorenzo L, FernandezHinojal G, et al. PD-L1 Signals through Conserved Sequence Motifs to 
Overcome Interferon-Mediated Cytotoxicity. Cell Rep. 2017;20(8):1818-29. Available from: https://doi.org/10.1016/j.celrep.2017.07.075. [cited 2020 Jul 29].

30. Kuipers H, Muskens F, Willart M, Hijdra D, van Assema FBJ, Coyle AJ, et al. Contribution of the PD-1 ligands/PD-1 signaling pathway to dendritic cellmediated CD4+ cell activation. Eur J Immunol. 2006;36(9):2472-82.

31. Dong $\mathrm{H}$, Strome SE, Matteson EL, Moder KG, Flies DB, Zhu G, et al. Costimulating aberrant $\mathrm{T}$ cell responses by $\mathrm{B} 7-\mathrm{H} 1$ autoantibodies in rheumatoid arthritis. J Clin Invest. 2003;111(3):363-70.

32. Oestreich KJ, Yoon H, Ahmed R, Boss JM. NFATc1 Regulates PD-1 Expression upon T Cell Activation. J Immunol. 2008;181(7):4832-9.

33. Mathieu M, Cotta-Grand N, Daudelin JF, Thébault P, Labrecque N. Notch signaling regulates PD-1 expression during CD8+ T-cell activation. Immunol Cell Biol. 2013;91(1):82-8

34. Rao RR, Li Q, Bupp MRG, Shrikant PA. Transcription Factor Foxo1 Represses T-bet-Mediated Effector Functions and Promotes Memory CD8 + T Cell Differentiation. Immunity. 2012;36(3):374-87.

35. Kao C, Oestreich KJ, Paley MA, Crawford A, Angelosanto JM, Ali MAA, et al. Transcription factor T-bet represses expression of the inhibitory receptor PD-1 and sustains virus-specific CD8+ T cell responses during chronic infection. Nat Immunol. 2011;12(7):663-71.

36. Bally APR, Lu P, Tang Y, Austin JW, Scharer CD, Ahmed R, et al. NF-kB Regulates PD-1 Expression in Macrophages. J Immunol. 2015;194(9):4545-54. Available from: http://www.jimmunol.org/content/194/9/4545. [cited 2020 Mar 29].

37. Kinter AL, Godbout EJ, McNally JP, Sereti I, Roby GA, O'Shea MA, et al. The Common $y$-Chain Cytokines IL-2, IL-7, IL-15, and IL-21 Induce the Expression of Programmed Death-1 and Its Ligands [Internet]. J Immunol. 2008;181. Available from: https://www.jimmunol.org. [cited 2020 Mar 29].

38. Sun Z, Fourcade J, Pagliano O, Chauvin JM, Sander C, Kirkwood JM, et al. IL10 and PD-1 cooperate to limit the activity of tumor-specific CD8+ T cells. Cancer Res. 2015;75(8):1635-44.

39. Park BV, Freeman ZT, Ghasemzadeh A, Chattergoon MA, Rutebemberwa A, Steigner J, et al. TGFß1-mediated SMAD3 enhances PD-1 expression on antigen-specific T cells in cancer. Cancer Discov. 2016;6(12):1366-81.

40. Nishimura $H$, Nose $M$, Hiai H, Minato $N$, Honjo T. Development of lupus-like autoimmune diseases by disruption of the PD-1 gene encoding an ITIM motif-carrying immunoreceptor. Immunity. 1999:11(2):141-51.

41. Nishimura $\mathrm{H}$, Honjo T, Minato N. Facilitation of $\beta$ selection and modification of positive selection in the thymus of PD-1-deficient mice. J Exp Med. 2000;191(5):891-7.

42. Jiang TT, Martinov T, Xin L, Kinder JM, Spanier JA, Fife BT, et al. Programmed Death-1 Culls Peripheral Accumulation of High-Affinity Autoreactive CD4 T Cells to Protect against Autoimmunity. Cell Rep. 2016;17(7):1783-94.

43. Honda T, Egen JG, Lämmermann T, Kastenmüller W, Torabi-Parizi P, Germain RN. Tuning of Antigen Sensitivity by T Cell Receptor-Dependent Negative Feedback Controls T Cell Effector Function in Inflamed Tissues. Immunity. 2014;40(2):235-47.

44. Fife BT, Pauken KE, Eagar TN, Obu T, Wu J, Tang Q, et al. Interactions between PD-1 and PD-L1 promote tolerance by blocking the TCR-induced stop signal. Nat Immunol. 2009;10(11):1185-92.

45. Fife BT, Guleria I, Bupp MG, Eagar TN, Tang Q, Bour-Jordan H, et al. Insulininduced remission in new-onset NOD mice is maintained by the PD-1-PD-L1 pathway. J Exp Med. 2006;203(12):2737-47.

46. Ahn E, Araki K, Hashimoto M, Li W, Riley JL, Cheung J, et al. Role of PD-1 during effector CD8 T cell differentiation. Proc Natl Acad Sci U S A. 2018; 115(18):4749-54.

47. Pauken KE, Nelson CE, Martinov T, Spanier JA, Heffernan JR, Sahli NL, et al. Cutting Edge: Identification of Autoreactive CD4 + and CD8 + T Cell Subsets Resistant to PD-1 Pathway Blockade. J Immunol. 2015;194(8):3551-5.

48. Roncador G, Brown PJ, Maestre L, Hue S, Martínez-Torrecuadrada JL, Ling KL, et al. Analysis of FOXP3 protein expression in human CD4+CD25+ regulatory $T$ cells at the single-cell level. Eur J Immunol. 2005;35(6):1681-91. Available from: https:/pubmed.ncbi.n/m.nih.gov/15902688/. [cited 2020 Aug 12].

49. Francisco LM, Salinas VH, Brown KE, Vanguri VK, Freeman GJ, Kuchroo VK, et al. PD-L1 regulates the development, maintenance, and function of induced regulatory T cells. J Exp Med. 2009;206(13):3015-29. Available from: https://pubmed.ncbi.nlm.nih.gov/20008522/. [cited 2020 Aug 12].

50. Amarnath S, Mangus CW, Wang JCM, Wei F, He A, Kapoor V, et al. The PDL1-PD1 axis converts human T H1 cells into regulatory T cells. Sci Transl Med. 2011;3(111):111ra120. Available from: https://www.pmc/articles/ PMC3235958/?report=abstract. [cited 2020 Aug 12].

51. Gotot J, Gottschalk C, Leopold S, Knolle PA, Yagita H, Kurts C, et al. Regulatory $T$ cells use programmed death 1 ligands to directly suppress autoreactive B cells in vivo. Proc Natl Acad Sci U S A. 2012;109(26):10468-73. Available from: https://www.pmc/articles/PMC3387068/?report=abstract. [cited 2020 Aug 12].

52. Gordon SR, Maute RL, Dulken BW, Hutter G, George BM, McCracken MN et al. PD-1 expression by tumour-associated macrophages inhibits phagocytosis and tumour immunity. Nature. 2017;545:495-9.

53. Lim TS, Chew V, Sieow JL, Goh S, Yeong JPS, Soon AL, et al. PD-1 expression on dendritic cells suppresses CD8+T cell function and antitumor immunity. Oncoimmunology. 2016;5(3).

54. Zhao Y, Harrison DL, Song Y, Ji J, Huang J, Hui E. Antigen-Presenting CellIntrinsic PD-1 Neutralizes PD-L1 in cis to Attenuate PD-1 Signaling in T Cells. Cell Rep. 2018.

55. Okazaki T, Maeda A, Nishimura H, Kurosaki T, Honjo T. PD-1 immunoreceptor inhibits B cell receptor-mediated signaling by recruiting src homology 2-domain-containing tyrosine phosphatase 2 to phosphotyrosine. Proc Natl Acad Sci U S A. 2001;98(24):13866-71.

56. Wang X, Wang G, Wang Z, Liu B, Han N, Li J, et al. PD-1-expressing B cells suppress CD4 + and CD8 + T cells via PD-1/PD-L1-dependent pathway. Mol Immunol. 2019;109:20-6.

57. Oliver KM, Garvey JF, Ng CT, Veale DJ, Fearon U, Cummins EP, et al. Hypoxia activates NF-kB-dependent gene expression through the canonical signaling pathway. Antioxid Redox Signal. 2009;11(9):2057-64.

58. Gao W, McCormick J, Connolly M, Balogh E, Veale DJ, Fearon U. Hypoxia and STAT3 signalling interactions regulate pro-inflammatory pathways in rheumatoid arthritis. Ann Rheum Dis. 2015;74(6):1275-83 Available from: http://www.ncbi.nlm.nih.gov/pubmed/24525913.

59. Gao W, Sweeney C, Connolly M, Kennedy A, Ng CT, McCormick J, et al. Notch-1 mediates hypoxia-induced angiogenesis in rheumatoid arthritis. Arthritis Rheum. 2012;64(7):2104-13. Available from: https://doi.org/10.1002/ art.34397. [cited 2020 Mar 26].

60. Patsoukis N, Bardhan K, Chatterjee P, Sari D, Liu B, Bell LN, et al. PD-1 alters T-cell metabolic reprogramming by inhibiting glycolysis and promoting lipolysis and fatty acid oxidation. Nat Commun. 2015;6(1):1-13.

61. Bengsch B, Johnson AL, Kurachi M, Odorizzi PM, Pauken KE, Attanasio J, et al. Bioenergetic Insufficiencies Due to Metabolic Alterations Regulated by the Inhibitory Receptor PD-1 Are an Early Driver of CD8+ T Cell Exhaustion. Immunity. 2016;45(2):358-73.

62. Ogando J, Saéz ME, Santos J, Nuevo-Tapioles C, Gut M, Esteve-Codina A, et al. PD-1 signaling affects cristae morphology and leads to mitochondrial dysfunction in human CD8+ T lymphocytes. J Immunother Cancer. 2019;7(1).

63. Guo Y, Walsh AM, Canavan M, Wechalekar MD, Cole S, Yin X, et al. Immune checkpoint inhibitor PD-1 pathway is down-regulated in synovium at various stages of rheumatoid arthritis disease progression. PLoS One. 2018;13(2).

64. Raptopoulou AP, Bertsias G, Makrygiannakis D, Verginis P, Kritikos I, Tzardi M, et al. The programmed death 1/programmed death ligand 1 inhibitory pathway is up-regulated in rheumatoid synovium and regulates peripheral T cell responses in human and murine arthritis. Arthritis Rheum. 2010;62(7):1870-80. Available from: http://doi.wiley.com/10.1002/art.27500. [cited 2020 Mar 2].

65. Bommarito D, Hall C, Taams LS, Corrigall VM. Inflammatory cytokines compromise programmed cell death-1 (PD-1)-mediated T cell suppression in inflammatory arthritis through up-regulation of soluble PD-1. Clin Exp Immunol. 2017;188(3):455-66.

66. Greisen SR, Yan Y, Hansen AS, Venø MT, Nyengaard JR, Moestrup SK, et al. Extracellular vesicles transfer the receptor programmed death-1 in rheumatoid arthritis. Front Immunol. 2017;8(JUL).

67. Wan B, Nie H, Liu A, Feng G, He D, Xu R, et al. Aberrant Regulation of Synovial T Cell Activation by Soluble Costimulatory Molecules in Rheumatoid Arthritis. J Immunol. 2006;177(12):8844-50 Available from: http://www.jimmunol.org/ lookup/doi/10.4049/jimmunol.177.12.8844. [cited 2019 Nov 13].

68. Moret FM, van der Wurff-Jacobs KMG, Bijlsma JWJ, Lafeber FPJG, van Roon JAG. Synovial T cell hyporesponsiveness to myeloid dendritic cells is reversed by preventing PD-1/PD-L1 interactions. Arthritis Res Ther. 2014;16(6).

69. Luo Q, Ye J, Zeng L, Luo Z, Deng Z, Li X, et al. Elevated expression of PD-1 on T cells correlates with disease activity in rheumatoid arthritis. Mol Med Rep. 2018;17(2): 3297-305.

70. Hatachi S, Iwai Y, Kawano S, Morinobu S, Kobayashi M, Koshiba M, et al. CD4+ PD-1+ T cells accumulate as unique anergic cells in rheumatoid arthritis synovial fluid. J Rheumatol. 2003:30(7):1410-9.

71. Li S, Liao W, Chen M, Shan S, Song Y, Zhang S, et al. Expression of programmed death-1 (PD-1) on CD4+ and CD8+ T cells in rheumatoid arthritis. Inflammation. 2014;37(1):116-21. 
72. Bartosińska J, Zakrzewska E, Purkot J, Michalak-Stoma A, Kowal M, Krasowska D, et al. Decreased blood CD4+PD-1+ and CD8+PD-1+ T cells in psoriatic patients with and without arthritis. Postep Dermatologii i Alergol. 2018; 35(4):344-50.

73. Kong EKP, Prokunina-Olsson L, Wong WHS, Lau CS, Chan TM, AlarcónRiquelme $\mathrm{M}$, et al. A new haplotype of PDCD1 is associated with rheumatoid arthritis in Hong Kong Chinese. Arthritis Rheum. 2005;52(4): 1058-62.

74. Sugiura D, Maruhashi T, Okazaki IM, Shimizu K, Maeda TK, Takemoto T, et al. Restriction of PD-1 function by cis-PD-L1/CD80 interactions is required for optimal T cell responses. Science (80-). 2019;364(6440):558-66.

75. Canavan M, Walsh AM, Bhargava V, Wade SM, McGarry T, Marzaioli V, et al. Enriched Cd141+ DCs in the joint are transcriptionally distinct, activated, and contribute to joint pathogenesis. JCI Insight. 2018;3(23) Available from: https://insight.jci.org/articles/view/95228. [cited 2019 Jun 19].

76. Petrelli A, Mijnheer G, Hoytema Van Konijnenburg DP, Van Der Wal MM, Giovannone B, Mocholi E, et al. PD-1+CD8+ T cells are clonally expanding effectors in human chronic inflammation. J Clin Invest. 2018; 128(10):4669-81.

77. Braaten TJ, Brahmer JR, Forde PM, Le D, Lipson EJ, Naidoo J, et al. Immune checkpoint inhibitor-induced inflammatory arthritis persists after immunotherapy cessation. Ann Rheum Dis. 2019.

78. Belkhir R, Le Burel S, Dunogeant L, Marabelle A, Hollebecque A, Besse B, et al. Rheumatoid arthritis and polymyalgia rheumatica occurring after immune checkpoint inhibitor treatment. Ann Rheum Dis. 2017;76(10):1747-50.

79. Goldstein BL, Gedmintas L, Todd DJ. Concise communication. Arthritis Rheumatol. 2014;66(3):768-9.

80. Cappelli LC, Gutierrez AK, Baer AN, Albayda J, Manno RL, Haque U, et al. Inflammatory arthritis and sicca syndrome induced by nivolumab and ipilimumab. Ann Rheum Dis. 2017;76(1):43-50.

81. Calabrese C, Kirchner E, Kontzias K, Velcheti V, Calabrese LH. Rheumatic immune-related adverse events of checkpoint therapy for cancer: Case series of a new nosological entity. RMD Open. 2017;3(1):e000412.

82. Buder-Bakhaya K, Benesova K, Schulz C, Anwar H, Dimitrakopoulou-Strauss A, Weber TF, et al. Characterization of arthralgia induced by PD-1 antibody treatment in patients with metastasized cutaneous malignancies. Cancer Immunol Immunother. 2018:67(2):175-82

83. Kostine M, Rouxel L, Barnetche T, Veillon R, Martin F, Dutriaux C, et al. Rheumatic disorders associated with immune checkpoint inhibitors in patients with cancer-clinical aspects and relationship with tumour response: a single-centre prospective cohort study. Ann Rheum Dis. 2018;77(3):393-8.

84. Cappelli LC, Brahmer JR, Forde PM, Le DT, Lipson EJ, Naidoo J, et al. Clinical presentation of immune checkpoint inhibitor-induced inflammatory arthritis differs by immunotherapy regimen. Semin Arthritis Rheum. 2018; 48(3):553-7. Available from: https://doi.org/10.1016/j.semarthrit.2018.02.011. [cited 2020 Apr 9].

85. Lidar M, Giat E, Garelick D, Horowitz Y, Amital H, Steinberg-Silman Y, et al. Rheumatic manifestations among cancer patients treated with immune checkpoint inhibitors. Autoimmun Rev. 2018;17(3):284-9.

86. Bertrand A, Kostine M, Barnetche T, Truchetet ME, Schaeverbeke T. Immune related adverse events associated with anti-CTLA-4 antibodies: Systematic review and meta-analysis. BMC Med. 2015;13(1).

87. Roberts J, Smylie M, Walker J, Basappa NS, Chu Q, Kolinsky M, et al. Hydroxychloroquine is a safe and effective steroid-sparing agent for immune checkpoint inhibitor-induced inflammatory arthritis. Clin Rheumatol. 2019;38(5):1513-9.

88. Kim ST, Tayar J, Trinh VA, Suarez-Almazor M, Garcia S, Hwu P, et al. Successful treatment of arthritis induced by checkpoint inhibitors with tocilizumab: a case series. Ann Rheum Dis. 2017;76(12):2061-4.

89. Perez-Ruiz E, Minute L, Otano I, Alvarez M, Ochoa MC, Belsue V, et al. Prophylactic TNF blockade uncouples efficacy and toxicity in dual CTLA-4 and PD-1 immunotherapy. Nature. 2019;569(7756):428-32. Available from: https://doi.org/10.1038/s41586-019-1162-y. [cited 2020 Aug 7].

\section{Publisher's Note}

Springer Nature remains neutral with regard to jurisdictional claims in published maps and institutional affiliations.

\section{Ready to submit your research? Choose BMC and benefit from}

- fast, convenient online submission

- thorough peer review by experienced researchers in your field

- rapid publication on acceptance

- support for research data, including large and complex data types

- gold Open Access which fosters wider collaboration and increased citations

- maximum visibility for your research: over $100 \mathrm{M}$ website views per year

At BMC, research is always in progress.

Learn more biomedcentral.com/submissions 